\title{
AS REPRESENTAÇÕES SOCIAIS DA MULHER NO MOVIMENTO HIP HOP'
}

\author{
Priscila Saemi Matsunaga \\ Universidade Federal de Goiás, Jataí, Brasil
}

\begin{abstract}
RESUMO: Este artigo discute as representações sociais da mulher construídas pelo movimento hip hop. Este movimento constitui-se como uma possibilidade de manifestação política de jovens, bem como uma possibilidade de produção artística que, se inicialmente esteve mais presente em espaços não institucionalizados e voltados para a população que vive na periferia, atualmente é consumido por jovens de camadas econômicas distintas. A participação de mulheres, porém, ainda não é significativa (ainda que existam mulheres participando) e ouve-se frequentemente músicas (ou raps) que veiculam imagens negativas da mulher. Este estudo, portanto, analisa as representações sociais da mulher que estão presentes em letras de rap, problematizando como estas representações constroem, socialmente, modos de "ser" mulher.
\end{abstract}

PALAVRAS-CHAVE: Movimento hip hop; representações sociais; mulheres.

\section{WOMAN'S SOCIAL REPRESENTATIONS IN THE HIP-HOP MOVEMENT}

\begin{abstract}
This paper discusses woman's social representations constructed by the hip-hop movement. This movement constitutes a possibility of younger generations to politically manifest themselves, as well as a possibility of artistic production that at the start was more present in non-institutionalized spaces and aimed at the populations living in marginal districts, it is now being currently consumed by youths of distinct social classes. However, the participation of women has not been significant (even though there are women taking part), and frequently negative images of women are conveyed from these songs (or raps). Thus, this study analyses the woman's social representations which are in rap lyrics, querying how such representations have built social ways of "being" a woman.
\end{abstract}

KEYWORDS: The hip-hop movement; social representations; women.

A maioria dos estudos acadêmicos situa a origem do movimento hip hop no bairro do Bronx, em Nova Iorque, durante a década de 1970, com a "união" dos elementos artísticos - a música rap, o break e o grafite (Andrade, 1996; Guasco, 2001; Guimarães, 1998; Lourenço, 2002; Magro, 2002; Rose, 1997; Silva, 1999; Tella, 1999, 2000, entre outros) e destaca sua importância social, cultural e política nas experiências juvenis contemporâneas.

Jovens negros e latinos, frente ao desemprego e a violência, (re)elaboraram suas práticas culturais e iniciaram manifestações artísticas que permitiram a construção de um sistema simbólico que orientava suas vivências e atitudes forjando o que posteriormente foi chamado de movimento hip hop (Silva, 1999).

Nos Estados Unidos e no Brasil, inicialmente, os elementos que hoje constituem o hip hop estavam mais direcionados ao lazer, ao divertimento, e como mecanismo de contenção da violênci. Porém, por meio do aprimo- ramento dos elementos artísticos e das organizações dos grupos de dança e música, que no hip hop denominam-se "posses" ou crews (grupos de dança ou grafite) que o movimento emergiu como uma organização social capaz de unir os jovens em manifestações artísticas que propiciam uma interpretação política de sua própria condição. Eles relatam as carências materiais da periferia, buscando reverter esta situação através de eventos beneficentes, utilizando a arte como instrumento de contestação da vivência periférica, trazendo para o discurso público as condições da população. Nas "posses", os grupos se articulam para promoverem shows, manifestações, oficinas e grupos de discussão sobre temas, principalmente, relacionados à condição do negro e aos problemas enfrentados na periferia pela juventude (Andrade, 1996).

Os sujeitos/atores que compõem cada elemento são: o MC (mestre de cerimônia - cantor ou rapper), o DJ (disc-jóquei), o b. boy ou b. girl (dançarinos) e os grafiteiros e grafiteiras. 
No Brasil, o movimento hip hop, enquanto manifestação político-cultural sustenta-se em suas expressões artísticas e em momentos de discussão e debates promovidos entre os próprios integrantes, ou em momentos em que reivindicam direitos junto ao poder público. $\mathrm{O}$ alcance dos elementos que compõe o movimento hip hop é nacional, pois ainda que as pessoas não pertençam a este grupo/movimento e não consigam identificá-lo como um movimento social, é possível que já tenham escutado rap e tenham visto sua dança em chamadas televisivas. Assim, o discurso produzido pelo movimento é veiculado não só entre seus integrantes, mas entre a população que tem acesso a suas expressões. A música rap, a dança de rua (break) e o grafite são manifestações artísticas que, isoladamente, não compõe o movimento hip hop.

O presente artigo pretende trazer algumas discussões quanto à representação social da mulher em letras de rap.

\section{Segundo McLaren (2000):}

Influenciado pela música de Curtis Mayfield, o funk de James Brown, o be-bop e o jazz rítmico, o rap é uma amálgama impressionante de formações musicais complexas. Alguns etnomusicólogos consideram tais formações como sendo expressões das formas expressivas africanas, como playing the dozens e signifying, assim como as canções de louvor dos contadores de histórias africanos, ou griot. No entanto, ao dizer isto, no entanto, não nos esqueçamos da importante afirmação de Tricia Rose, de que o hiphop não deve ser reduzido às suas origens musicais ou tradições africanas. O hip-hop precisa ser entendido, argumenta Rose, como uma 'segunda oralidade' dentro de uma realidade mediada eletronicamente, que está conjunturalmente embutida em relações de poder e políticas. (p. 161).

É necessário salientar que este estudo volta-se aos grupos de rap que são considerados como pertencentes ao hip hop (na perspectiva de seus integrantes) e se inscreve nas discussões acerca dos Novos Movimentos Sociais ${ }^{2}$.

Faz-se necessário também esclarecer alguns conceitos que perpassaram o estudo. Ao fazer referência às representações sociais, a partir das contribuições de Serge Moscovici (2003), evidencio que o discurso comporta formas de significação da realidade ao mesmo tempo em que são produzidas por esta(s) realidade(s), não considerando os sujeitos sociais somente como reprodutores dos significados presentes na cultura, mas também produzindo novos sentidos. No diálogo entre o conceito de representações sociais (presente na Psicologia Social) e identidades (Estudos Culturais), pensamos que:

O sujeito é constituído no interior da representação. Isto equivale dizer que as identidades sociais são um resultado de um processo de identificação que permite que nos posicionemos no interior das definições que os discursos culturais (exteriores) fornecem ou que nos subjetivemos (dentro deles). Nossas chamadas subjetividades são, então, produzidas parcialmente de modo discursivo e dialógico. (Guareschi \& Bruschi, 2003, p. 45).

Desta forma, ao salientar as representações sociais da mulher presentes nas letras de rap mostro como o movimento hip hop constrói identidades de gênero. Compreendo o conceito de gênero como, ainda que existam questionamentos sobre a utilização da categoria gênero, a diferenciação sexual determinando os papéis e lugares sociais. Segundo Castro (2001):

De qualquer modo, há alguns vazios entre a intenção teórica e o uso empírico do conceito, observado por Heilborn. Algumas feministas envolvidas no debate teórico, sob a influência francesa, põem mais ênfase sobre as diferenças. Heilborn, por exemplo, defende que o termo gênero pode indicar relações de oposição, desde que o conceito empregue uma 'forma elementar de diversidade'. Outros autores enfatizam as relações sociais de poder. Para muitas o conceito foi útil ao permitir enfocar as relações sociais de poder e o processo de construção da subordinação das relações entre homens e mulheres, assim como entre mulheres e homens com o aparato do Estado. Para outras, como mencionado, é uma forma de abordagem sobre diversidades e diferenças, e para algumas autoras, é uma forma de tratar com sistemas múltiplos de desigualdades e dominação, nos níveis simbólicos e materiais. (p. 57- 58).

Não há ainda um consenso quanto à definição do conceito de gênero. Este conceito, porém, nos ajuda a compreender como a constituição "ser homem"/"ser mulher" é atravessada pela naturalização do feminino e masculino e isto engendrando relações de poder. Esta distinção também nos remete à compreensão de outra categoria que atravessa a análise das letras de rap, a "sexualidade". Sexualidade aqui compreendida como uma construção social, a partir de uma abordagem sócio-antropológica, portanto circunscrita pelas representações culturais de cada grupo social e pelas transformações históricas, bem como referenciando compreensões acerca do corpo e das práticas sexuais.

\section{O desenvolvimento da pesquisa}

Durante as primeiras investigações sobre o hip hop, observando shows e eventos promovidos pelos jovens, havia uma tímida participação de mulheres no movimento. Nestes momentos de diversão, as mulheres quase sempre "acompanhavam" os homens. Esta (in)visibilidade levou-me a investigar a participação e as representações 
sociais acerca da mulher presentes no hip hop. Assim, no presente artigo problematizo a representação da mulher no movimento, utilizando as letras de rap como fonte de dados para análise, uma vez que a música rap é a expressão artística com maior visibilidade, maior número de produtores e ouvintes, fazendo circular com maior alcance os significados e sentidos presentes no movimento, incluindo aí os significados atribuídos à mulher.

Procurei identificar grupos de rap que são "representativos" no cenário nacional, conversando com integrantes do movimento hip hop em Piracicaba e São Paulo, bem como com lojistas que indicaram os grupos "mais vendidos" (tanto na cidade de Piracicaba, quanto em São Paulo, na galeria 24 de Maio), além de consultar sites destinados ao público hip hopper.

Optei por letras que produzissem discursos sobre a mulher entre os grupos indicados pelos integrantes. São letras que, já no título, se referem à mulher ou que no decorrer da letra fazem algum tipo de referência. Os grupos escolhidos e as letras foram:

Face da morte: Mulheres; Ndee Naldinho: Aquela mina é firmeza e O Filho adotivo; Facção Central: Desculpa mãe; Gabriel o Pensador: Loraburra; Racionais MC's: Mulheres Vulgares, Parte II, Fórmula Mágica da Paz, Qual mentira vou acreditar; Rappin'Hood: Tributo às mulheres negras; MV Bill: Soldado Morto, Mina de Fé; Detentos do rap: Amor... Só de mãe.

Para que as análises das letras pudessem refletir possíveis diferenciações entre as produzidas por homens e mulheres, recorremos a produção da Rapper Nega Gizza, Lady Rap e do grupo que possui como uma de suas MC's, e principal letrista (Dina Di), Visão de Rua. As letras de "mulheres" são:

Lady Chris: Guerreira; Visão de rua: Abertura, Dina Di 2004, Amor e Ódio, Corpo em evidência, Hora de avançar, Vem vê, A noiva do Thock, Memórias, Filho pro mundo, Guerreiros..., Marcas da Adolescência (estas letras compõem o CD A Noiva do Thock); Nega Gizza: Filme de terror, Depressão, Larga o Bicho, Prostituta, Neném, Inconstante, Fiel Bailarino (letras que compõem o CD Na Humildade).

Foram, portanto, utilizadas como fonte de dados 32 letras de rap. As que foram analisadas não compõem a totalidade da produção, nem tampouco compreendem todas as possibilidades de representação da mulher que podem existir neste cenário, bem como as diferenciações que perpassam o rap3. Preocupei-me, porém, com os significados atribuídos à mulher referentes às possíveis identidades que a distinção de gênero pudesse sugerir. Em um primeiro procedimento de organização dos dados, houve uma tentativa de interpretação dos sentidos dos conteúdos de cada letra, que poderíamos chamar de "interpretação descritiva". Posteriormente, realizei uma categorização desenvolvida a partir desta primeira orga- nização. Esta categorização, ainda empírica, buscou fornecer dados para discutir sobre as possíveis identidades atribuídas à mulher, referentes à raça/etnia, classe social, valores morais e papéis sociais. Estas características estão presentes nas letras por meio de adjetivações, imagens, expressões que, no jogo discursivo, atuam distinguindo "quem sou eu/nós", "quem é o outro/eles", convencionando as "concepções" de mundo, construindo relações e produzindo ou reproduzindo estereótipos.

Após a realização desta primeira categorização propomos a discussão analítica baseada em três categorias: ser mãe, ser mulher objeto e ser lutadora. Durante o processo de análise percebemos que as letras refletiam as ideologias 4 e idealizações que permeiam a construção da distinção de gênero no movimento hip hop.

\section{Os sentidos da "mulher" nas letras de Rap}

Se compararmos as produções entre homens e mulheres, percebemos que as letras escritas por mulheres falam sobre suas experiências pessoais, quem são, onde vivem, revelando como se vêem, como constroem suas identidades. As letras dos homens possuem um conteúdo, de forma geral, mais abrangente, acontecimentos que ocorreram no bairro, com outros e com eles mesmos. Esta forma de construção de narrativas, porém, não é "exclusividade" dos homens (Nega Gizza possui letras mais abrangentes), mas está mais presente na produção destes. Podemos pensar que esta distinção fornece dados sobre como as mulheres exercem em sua fala o direito de expressar sobre suas próprias experiências.

Esta publicização pode operar como um questionamento da própria construção social de ser mulher. Aponta para uma dimensão pública onde o privado "reinava", entendendo a dimensão do "privado" relacionado ao espaço da casa5 (e aos papéis de mãe, esposa e dona-de-casa), e à dimensão pública na possibilidade da mulher desempenhar papéis e funções relacionadas à "rua", como, por exemplo, o poder público (subir a rampa de acesso - letra Lady Rap). Assim, representações identitárias são apresentadas para que outros sentidos da vivência da mulher sejam construídos.

Como proposto pela Teoria das Representações Sociais (Moscovici, 2003), para a compreensão das representações, os rappers, e mais especificamente as rappers, compartilham representações já arraigadas, mas contribuem na formação de novas representações ao instituir elementos novos, divulgando outras formas de compreensão da mulher, que, além de ser mãe e companheira, também se organiza em grupos e luta, propondo, portanto, referências na construção do mundo e da mulher. Possibilidades de referência para as pessoas que escutam estas letras compreendam o movimento hip hop e a mulher que nele habita. 
A partir das características na construção identitária da mulher as/os rappers definem "ideais" de mulher que definem "quem é quem" no jogo das relações sociais. Quem pertence ao "meu" grupo, sendo homem ou mulher, quem pertence ao grupo do "outro". Interessa-nos compreender como estes ideais reiteram, ou não, sentidos da mulher e como estes sentidos operam na construção do movimento hip hop.

\section{Ideais de mulher}

\section{Amor... só de mãe}

A mãe é o tipo/personagem mais valorizado pelos rappers, sendo muito exaltada nas letras. Seu sofrimento, sua luta pra manter a família e os filhos unidos, sua dedicação é detalhada, e diria idealmente configurado. Esta personagem é envolta em uma "áurea" que a transforma em quase uma santa. Ela é capaz de sofrer, quase morrer e perdoar as "irresponsabilidades" do filho de "coração sempre aberto". Configura-se, portanto, uma reiteração de um imaginário sobre as funções sociais da mulher, em especial, o cuidado com os filhos.

O discurso no qual se assenta a ideologia de que a "mãe" é a responsável pela "criação" dos filhos é definida, segundo Lipovetsky (2000), pela associação direta em ser mulher e o amor. A "mãe" hip hopper assume este amor, que lhe é destinado, como natural. Assim também o é para as mulheres rappers. Segundo as letras femininas, a mãe espera que seu filho não "vire marginal", por causa das companhias erradas, pois ela fez de tudo para alimentá-lo e educá-lo, como, por exemplo, prostituir-se. É por meio deste ato que ela demonstra o seu amor, reiterando, portanto, a representação de que a mãe doa-se ao filho e existe em função dele.

Interessante registrar que uma pesquisa realizada por Elizabeth Badinter (1980), citada por Saffioti (2004), na qual mulheres eram questionadas sobre a maternidade, $55 \%$ das entrevistadas valorizavam esta condição, porém " $48 \%$ valorizavam a maternidade mesma, isto é, o fato biológico, pois só $20 \%$ mencionaram o prazer enorme propiciado pela maternagem" (p. 47).

Podemos pensar que maternidade, e a figura da mãe, portanto, continua sendo um modelo identificatório para a construção da identidade da mulher baseada em seu aspecto biológico, determinando que ser mãe seja "sina" para muitas mulheres em virtude de sua condição biológica (Sarti, 1985), e reiterando a construção de um imaginário que associa esta "condição" ao amor "incondicional", ou seja, uma construção social (a partir do componente biológico) considerada uma condição natural (toda mãe ama).

Para além desta possibilidade de compreensão do sentido da mulher como mãe, ou seja, entendendo que o hip hop mantém uma imagem da mulher de forma con- servadora, associando-a ao espaço privado e ao cuidado do outro (filhos e maridos), podemos pensar que nas letras de rap a condição econômica da qual os/as rappers falam e vivenciam influencia na construção do "ser mãe". Segundo Mano Brown, integrante do grupo Racionais MC's, em entrevista no programa Ensaio, em 2003, transcrito por A. R. Souza (2005, p. 13): "Eu não tive pai. Como é que eu vou chamar outro homem de autoridade? Autoridade é a minha mãe."

Como ele, outro conhecido rapper, MV Bill, consideraque:

Porque as mães da favela, principalmente a mãe de baixa renda, pode faltar tudo, mas não falta o carinho e o amor . . . E uma das cenas mais chocantes que eu trago na memória, desse trabalho todo, de tudo o que eu vi, foi uma comunidade que a gente estava, em uma cidade aí, e de madrugada os garotos traficando, vendo a droga deles, chegou uma mãe trazendo como se fosse uma marmita pro filho no trabalho, sabe? Como se fosse um trabalho normal. Ela chegou: 'Oi, meu filho'. Deu beijo na testa dele, deu a marmita na mão dele e disse: 'Fica com Deus, meu filho, tchau, um beijo'. Deu tchau pra todo mundo e eu fiquei olhando aquilo ali e fiquei pensando se aquela mulher estava alimentando o filho dela ou se ela estava alimentando o tráfico de drogas . . . Conversei com outras mães que faziam isso, elas falavam: 'Meu filho, mesmo sabendo que ele tá errado, que aquele dinheiro é sujo, eu sou mãe!' E esse 'eu sou mãe' explica muita coisa. A figura da mãe pra nós é muito diferente. É difícil os caras da favela chamarem a mãe de você. É sempre senhora, é uma figura religiosa. Pela mãe, nego dá a vida, mata e morre. É isso que a gente aprende. Esses garotos que conversei, muitos não têm pai. O pai é ausente, o pai é preso, é alcoólatra, abandonou, simplesmente sumiu, pai morto. Mas a mãe está ali, é vista de forma heróica. Eu costumo chamar a mãe de pãe. Faz dois papéis ao mesmo tempo. (Entrevista explosiva, 2005).

A mãe é a autoridade na periferia. As mães, no contexto periférico, são a expressão de que o sujeito pode manter-se "firme" diante das adversidades da vida. Segundo Porto (2004), baseada em dados da pesquisa "A mulher brasileira nos espaços públicos e privado", realizada em 2001 pela Fundação Perseu Abramo, afirma que "76\% dos lares brasileiros as mulheres participam da composição da renda familiar, e 32\% deles são providos principalmente pelas mulheres" (p. 141).

Segundo Lima (2005), citando Scott (1990) “sob as condições de pobreza, os maridos não conseguem contribuir adequadamente para o sustento da casa nem as relações afetivas conseguem manter-se suficientemente satisfatórias para garantir a maioria das uniões" (p. 68).

Salienta a autora, discutindo o alto índice de casas chefiadas por mulheres e o conceito de matrifocalidade, que as relações mãe-filho são mais solidárias, fortalecendo o "lado" feminino do grupo familiar. 
Com base nestes dados, e considerando que a grande maioria dos rappers mora na periferia das cidades e possui uma condição financeira precária, compreendemos que a exaltação da "figura materna" de forma idealizada é construída na medida em que, no cotidiano, a mulher/mãe vem sendo cada vez mais a responsável pela manutenção familiar, em seu aspecto econômico e social. Os estereótipos que acompanham a construção social da "mãe", ou seja, seu amor incondicional, sua luta na formação moral do filho, o perdão que é concedido quanto este "erra", promovem a sensação de amparo e proteção.

Por parte das letras femininas, elas utilizam esta mãe idealizada como modelo identificatório na construção de sua condição materna. Ambos, portanto, (re)apresentam a mãe idealizada proposta pela ordem social moderna.

Khel (2000), em uma análise sobre a produção do

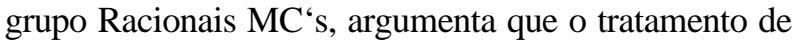
"mano" entre os hip hoppers significa um sentimento de fratria e um campo de identificações horizontais, bem como, a "utilização" de Deus funcionando como a interdição paterna.

E a mãe? Como podemos pensar a "função materna" a partir desta perspectiva? Segundo Pimentel (1999), "a única exigência definitiva é a lealdade à periferia, esta sim a grande mãe de todos os manos, acima de tudo" (p. 107).

O sentido atribuído à mãe, muitas vezes sobrepõese aos sentidos atribuídos à periferia. Neste espaço geográfico e simbólico, os hip hoppers se sentem protegidos. Na periferia existe uma lei paralela, todos a seguem. É na periferia que os "manos" conseguem redenção, após cometerem algum crime (a mãe/periferia em muitos casos é permissiva, assim como a mãe que perdoa o filho quanto este rouba, mata, trafica, não lhe impondo repreensões nem castigos); são perdoados e amados. Como o morro, cantado em muitos sambas de forma romantizada, é na mãe/periferia romantizada que os hip hoppers possuem um lugar de aconchego, de sossego, de carinho, de aprendizado, como no argumenta MV Bill:

Ter condições de vida subumana, criança desnutrida, sabe? Isso tudo não é bonito. Agora, no caso do rap, muitos caras que eu conheço falam da questão com uma certa nostalgia, por causa do aprendizado que tiveram naquela comunidade. Eu, por exemplo, quando falo da Cidade de Deus, lembro muito do aprendizado que tive. Se hoje sou alguma coisa é graças àquele lugar, até se me dei mal isso fez com que eu aprendesse alguma coisa para o futuro graças àquele lugar. (Entrevista explosiva, 2005).

Se a periferia é um espaço/modelo identificatório para a construção identitária hip hopper talvez seja pelo fato de que este espaço comporta sentidos que vão além da situação sócio-econômica e geográfica e simboliza a "mãe" de todos. Aquela que ama incondicionalmente, abriga e ampara.

Um sentido, portanto, desta "função materna" seria a compreensão de que o cuidado, o amor incondicional, é exercido por esta mãe/biológica e pela mãe/periferia. Numa sociedade desigual como a nossa, em que a maioria da população sofre dificuldades materiais e se estabelece no "mundo das necessidades"; simbolicamente, a mãe periférica fornece segurança e compreensão a todos que a ela recorrem. Para além de uma compreensão do "real" e da mãe reiterando uma representação conservadora sobre a mulher, os hip hoppers utilizam desta imagem para a representação de pelo menos um lugar/espaço simbólico no qual são valorizados.

\section{Você não passa de mulher objeto}

A mulher e sua sexualidade adquirem contornos distintos para o hip hop, pois de um lado a mulher é vista como "linda e sensual", em outros momentos como "promíscua e vulgar".

Em algumas letras há uma positivação da sexualidade feminina quando fala das mulheres negras. Exemplo disto é a música Tributo às mulheres negras, que, além de trazer questões que são realidade no nosso país, como a discriminação racial em relação à ocupação em postos mais elevados de trabalho e a quase inexistência de imagens positivadas do negro na mídia, trabalha também com uma essencialização da feminilidade da mulher negra.

Nesta positivação, opera uma compreensão de que ela é a "mulher brasileira", mantendo entre outras coisas uma representação da mulher sensual ("deixa fluir todo o seu perfume"). Não é mais a "mulata tipo exportação" da qual fala a letra Larga o bicho, de Nega Gizza, mas mantém-se a idéia de sensualidade e sexualidade inerente à mulher, em especial à mulher negra.

Como entender, então, a representação da mulher em relação à sua sexualidade? De certa forma, em relação a esta dimensão identitária, ocorre uma idealização da mulher como sendo sensual por natureza e pronta para o sexo. Isto está presente não somente na compreensão da mulher, mas do povo brasileiro em geral. Na pesquisa referida anteriormente realizada pela Fundação Perseu Abramo, uma das questões abordadas com as 2.502 entrevistadas, referia-se a sua satisfação sexual. Segundo Chacham e Maia (2004):

O primeiro dado que chama a atenção, ao analisar os resultados obtidos, é o número impressionantemente alto de mulheres que se declararam satisfeitas com a sua sexualidade ou vida sexual: $79 \%$ do total (incluindo aí $77 \%$ das virgens). Mais interessante ainda é que $61 \%$ do total afirmaram estar "totalmente satisfeitas" com a sexualidade . . . Parece-nos que o dis- 
curso de uma felicidade geral na cama reafirma nosso autoconceito de povo sensual e sexual. É fato a grande importância que brasileiros(as) conferem ao sexo e à sensualidade nas suas interpretações sobre si mesmos como povo. Se na Europa e nos Estados Unidos a vida sexual tem sido tratada como um fenômeno essencialmente individual, no Brasil ela foi tomada como uma espécie de chave para a "natureza" peculiar da realidade brasileira. (p. 76-77).

Os hip hoppers estariam, portanto, reiterando esta representação do povo brasileiro e da mulher brasileira como essencialmente "sensual". Nesta reapresentação, porém, utilizam esta dimensão de forma positivada ao falar da mulher negra e de forma negativa ao falar sobre a mulher branca (O grupo Racionais $M C$ 's não faz esta distinção).

É na ambigüidade deste discurso que está situada à representação da mulher e sua sexualidade, adotando em alguns momentos um discurso conservador e tradicional e em outros um discurso positivado desta mesma sexualidade. Existe uma moral para homens e outra para mulheres. Esta "dimensão sexualizada" da mulher ora é utilizada para positivação da mulher negra, substituindo o lugar da "mulata tipo exportação" (representação da mulher brasileira para o comércio do turismo e para o próprio brasileiro), ora é utilizada de forma negativa para caracterizar a mulher como promíscua. Em algumas letras percebemos que a sexualidade da mulher é vista como promiscuidade quando vivenciada livremente. Esta posição é adotada principalmente pelo grupo Racionais MC's. Segundo eles, pode-se "confiar na mulher somente 50\%", porque ela está sempre pronta pra ser infiel, trair o namorado/marido com outros homens, ter vários parceiros ao mesmo tempo. Esta promiscuidade permeia "qualquer tipo" de mulher, ou seja, "negra, branca ou mestiça". De forma geral há uma coisificação/objetivação da mulher. A vivência livre da sexualidade ainda não é vista pelo hip hop como um direito que a mulher conquistou a partir das lutas feministas. As mulheres ainda se mantêm "fiéis como um cão na ilha da sedução" (Dina Di), mesmo quando não correspondidas. É uma reapresentação do amor romântico, da fidelidade da mulher, da mulher dita "de família", em oposição à mulher "da rua", pois esta "é só pra uma noite" (Racionais MC's). Entendemos que a sexualidade ainda continua sendo um forte "tabu" entre os membros do movimento hip hop, e a vivência desta sexualidade sendo regida pelos valores tradicionais, conformando a construção da representação da mulher e sua identidade "sexual" em aspectos conservadores de uma ordem social estabelecida pelo: "patriarcalismo"; pela "religião" ("Eu vejo lúcifer de sutiã e calcinha, querendo dar o bote vestido de mulher e me separar da minha mina de fé", rapper MV Bill, letra Mina de Fé) e pela "medicina" - que define saúde/doença ("compulsivos por sexo vir- tual, uma epidemia sobre a qual ninguém fala, contamina a alma, é imoral, afeta e muito o estado emocional, provoca crise conjugal, separação, traição na vida real", grupo Visão de Rua, letra Corpo em Evidência).

Como o movimento hip hop ainda opera nesta dicotomia ("prostituta", "santa"), as mulheres, para se sentirem respeitadas e integrantes "efetivas" do movimento, também reproduzem esta dicotomia, ou seja, condenam as mulheres por estas se "colocarem" como objeto (letra Dina Di, Corpo em evidência). Este discurso indica que os sentidos sobre a mulher objeto são partilhados não somente pelos homens, mas também pelas mulheres.

\section{Tem que ser mulher pra se manter em pé}

Uma das características atribuídas à mulher é sua força, sua luta. Nas letras, esta dimensão aparece associada a uma condição de ser da periferia e de ser negra. A mulher, a não ser quando se trata da "mulher objeto", é vista como uma batalhadora, lutando e sofrendo com as adversidades da vida.

Pensamos que esta valorização da luta como modelo identificatório moral do hip hop, e da mulher no hip hop, possibilita uma inversão na construção social da periferia e da negritude como sendo marginais, malandros, ladrões, preguiçosos, bandidos...

Construir uma imagem positiva para esta população parece ser o objetivo do hip hop.

Segundo Herschmann (1997):

A música, tanto no funk quanto no hip-hop, é também uma das mais evidentes formas de inscrição da "cidade dos excluídos" no imaginário coletivo urbano. As letras, especialmente no hip-hop, denunciam um cotidiano difícil, projetando a realidade da favela ou subúrbio dos MCs por toda cidade. (p. 232).

Não que nas letras de rap a periferia não seja habitada por pessoas de "má índole" (como o "neguinho" em oposição "ao preto tipo A"), mas o discurso hip hopper enfrenta este estereótipo a partir de outro: o povo da periferia é um povo lutador. A mulher negra da periferia é uma mulher que "batalha, vive no dia-a-dia, faz as suas correrias". Esta positivação da periferia, a exaltação e autovalorização da pessoa que nela habita possibilita uma construção identitária também positivada.

Como seria possível a construção identitária positivada se aspectos que permeiam a vida do ser humano não fossem valorizados? Os sujeitos poderiam construir uma imagem de si positivada se todas as representações que lhe servem como identificação são vistas negativamente? O hip hop, em seu discurso público, oferece uma opção: valorize o "mano", a mulher que corre junto com você, a negritude, a periferia.

Constroem, portanto, para si, uma representação positivada, baseada numa dimensão moral valorizada pela 
sociedade brasileira, a humildade (herança religiosa do catolicismo?) e a luta (representação que permeia a luta dos escravos e suas formas de resistência).

Este valor produz sentidos para a vida cotidiana, que, baseada nas condições da população, só pode ser vivenciada como uma luta pela sobrevivência. O discurso hip hopper, portanto, opera como uma "resistência radical" (A. R. Souza, 2005) para a construção de um grupo de pertencimento positivado. A carência, as dificuldades são vencidas no dia-a-dia, no cotidiano. Valorizar a cultura, o hip hop, como sendo próprio deste grupo, funciona como alternativa para aqueles que foram renegados, destituídos da cultura "elitizada", dos teatros, da música erudita. O que lhes "resta" é uma cultura de rua, sem academias, sem títulos. Muito embora de forma idealizada, e romantizada, esta valorização da batalha, da luta como inerente à periferia e ao negro, fornece uma representação e modelos identificatórios.

Em relação às letras produzidas por mulheres, que também valorizam a mulher batalhadora, há uma afirmação que nega o imaginário social no qual ela é representada como frágil, passiva, dependente. As mulheres utilizam a "luta" como referência identitária na construção da representação da mulher que é "independente, que constrói o próprio nome" (Grupo Visão de Rua, letra Hora de Avançar).

Autoras de suas letras também são autônomas e autoras de suas próprias histórias. Esta representação da mulher fornece referências para outras mulheres ocuparem espaços diferenciados, como espaços públicos. Esta busca de sentido revela que, para além da reiteração de concepções tradicionais da mulher, estão presentes tanto no discurso feminino como em letras produzidas pelos hip hoppers (a mãe, a esposa, a fidelidade), a mulher é vista, pela mulher hip hopper, "conversando" com a agenda feminista que reivindica, entre outras coisas, direitos sociais igualitários.

\section{Considerações finais}

Ser hip hopper significa a positivação simbólica da periferia, da negritude, e em alguma dimensão, da masculinidade. E foi a partir desta inquietação, da dimensão sexista presente no movimento, que iniciamos este estudo. Seria muito problemático tecermos conclusões definitivas sobre a participação de mulheres no movimento, mas este estudo pretende compreender a representação de mulher oferecida pelos seus discursos.

As letras de rap, tanto femininas quanto masculinas, sugerem diferentes sentidos. A mulher presente no discurso do rap ocupa os papéis sociais de mãe e namorada, é valorizada por ser negra e batalhadora, é condenada por ser "objeto" e "vulgar". Estas características sugerem uma representação da mulher vinculada a uma ordem moral e social conservadora, que ainda opera na distinção entre feminino e masculino, atribuindo, para o primeiro, o espaço privado, e, para o segundo, o espaço público.

Segundo Lipovetsky (2000), muitas foram às transformações ocorridas, principalmente no século XX, que indicam o surgimento do que o autor chama de "terceira mulher". Esta concilia papéis sexuais tradicionais, como mãe e esposa, com uma possibilidade de "atuação pública e combativa" que muitas vezes the era negada, como a profissionalização e a busca pelo poder.

Como observa o autor, porém, permanece a distinção sexual num "duplo modelo individualista", na qual a mulher deve se inserir, por exemplo, no mercado de trabalho e nos postos de decisão política, e o homem deve estar mais interessado nos assuntos privados, a saber, o cuidado com a casa e com os filhos. Esta divisão, porém, ainda mantém um "núcleo" que coloca a distinção masculina/feminina nos espaços públicos para o primeiro, e os espaços privados para o segundo. Esta visão permanece no hip hop e no discurso das integrantes do movimento. Quais seriam os sentidos para tal posicionamento?

Entendo que, talvez, esta permanência de uma visão androcêntrica possua, pelo menos, dois sentidos. $\mathrm{O}$ primeiro seria a manutenção de poder. A "guerra dos sexos" no movimento se perpetua, principalmente na exposição artística. $\mathrm{O}$ embate entre homens e mulheres se dá quando eles a impedem de "aparecer" tanto quanto eles. Para o movimento, não é legítimo a mulher ir para o palco, uma vez que este espaço é reservado para os homens7. Se pensarmos na separação entre rua/casa, espaços públicos e privados, podemos inferir que existe uma distinção entre palco/bastidores.

Outro sentido que pode ser atribuído à manutenção de uma visão discriminatória em relação à mulher se refere à tentativa do movimento hip hop se incluir no discurso atual. O sexismo não é exclusividade do movimento. A sociedade brasileira estrutura-se a partir da visão androcêntrica, e isto pode ser observado nas distinções sexuais quanto aos postos de trabalho ocupado por homens/mulheres, a diferença de salários, a hierarquia política, entre outros. Isto não é negar os avanços conquistados pelas mulheres, mas admitir que as relações sociais contemporâneas perpetuam discriminações quanto à distinção sexual, definindo espaços que podem ser ocupados por homens e mulheres.

Entendemos que, de certa forma, o hip hop joga o jogo das relações de poder. O jovem que quer ser incluído, respeitado, reconhecido como sujeito, sendo ele pobre e negro, para a nossa sociedade, tem que também ser homem. A busca pela inclusão reforça aspectos que são valorizados socialmente em relação à mulher, ou seja, a mulher "doce", que é uma "boa" mãe, fiel ao marido, que 
enfrenta junto com ele as adversidades da vida. Esta representação não é exclusiva dos hip hoppers, mas ainda é uma representação da mulher no Brasil.

Para ser incluído, o "neguinho tipo A" tem ao lado uma "mina de fé" e, assim, nas letras de rap, percebemos que a construção identitária perpassa “... uma adjetivação de si no plano relacional com o outro, quer seja um outro semelhante ou oposto" (T. Souza, 2002, p. 72). O discurso hip hopper procura, portanto, o reconhecimento identitário e inclusão social realçando aspectos que não somente são valorizados pelos periféricos, mas pela sociedade em geral, utilizando nas letras referências positivas do homem, que tem ao seu lado uma "boa" mulher. Um exemplo disto se refere à sexualidade. A vivência da sexualidade por parte das mulheres de forma livre é um "tabu" não somente no hip hop. Esta dicotomia moral permanece no movimento, reforçando uma representação deste como um contexto moralmente aceitável, pois está em sintonia com os preceitos da sociedade brasileira.

Pretendemos, com estas considerações, salientar a importância de revermos os parâmetros que configuram as relações sociais, não somente ligadas às questões de classe, etnia/raça, mas também as relações de gênero.

O hip hop reivindica um reconhecimento identitário positivado, alicerçado na positivação da negritude e da periferia (ainda que estes se sobreponham em muitos casos), apresentando em seu discurso, para a efetivação desta positivação, discriminações de gênero que reforçam o discurso geral/público sobre a mulher. O sentimento e a tentativa de inclusão reiteram, portanto, em relação à distinção de gênero, a supremacia masculina. A tentativa de reverter este quadro está presente, principalmente, no discurso das mulheres que fazem parte do movimento e reivindicam para si outras representações e relações. Elas apontam, portanto, que o hip hop "pode" se configurar de outra maneira, mas isto dependerá de suas lutas, das reflexões e dos debates.

Entendemos, então, que o movimento hip hop se articula em diferentes demandas, entre elas a demanda de grupos feministas, o que sugere, portanto, que como um movimento social, o hip hop atua como uma mobilização que expõe as várias desigualdades sociais que perpassam a sociedade brasileira, sejam elas referentes a questões raciais, econômicas e, com os grupos feministas, as desigualdades engendradas pela discriminação de gênero.

\section{Notas}

1. Trabalho derivado de projeto de pesquisa desenvolvido durante o Mestrado em Educação na Universidade de Campinas (Unicamp), sob orientação do $\operatorname{Prof}^{\circ}$ Dr. Salvador Antonio Mireles Sandoval, com apoio da Coordenação de Aperfeiçoamento de Pessoal de Nível Superior (Capes).
2. Compreendemos o hip hop como uma forma de ação coletiva. Para uma discussão ampliada sobre os Novos Movimentos Sociais sugerimos a leitura de: Melucci, A. (2001). A invenção do presente. Movimentos sociais nas sociedades complexas. Petrópolis, RJ: Vozes.

3. Há estilos diferentes no rap, como o estilo gangsta rap ou gospel, entre outros. Não fizemos as diferenciações quanto ao estilo uma vez que os grupos foram selecionados a partir das referências dos próprios integrantes do hip hop, ou seja, aquilo que eles mais ouvem e consomem. Salientamos, porém, que os diferentes estilos possuem temas de interesse distintos e batidas diferenciadas.

4. Utilizamos o conceito de ideologia como proposto por J. B. Thompson (1995). "Argumentarei que o conceito de ideologia pode ser usado para se referir às maneiras como o sentido (significado) servem, em circunstâncias particulares, para estabelecer e sustentar relações de poder que são sistematicamente assimétricas - que eu chamarei de "relações de dominação". (p. 16).

5. Segundo DaMatta (1991) “Quando, então, digo que 'casa' e 'rua' são categorias sociológicas para os brasileiros, estou afirmando que, entre nós, estas palavras não designam simplesmente espaços geográficos ou coisas físicas mensuráveis, mas acima de tudo entidades morais, esferas de ação social, províncias éticas dotadas de positividade, domínios culturais institucionalizados e, por causa disso, capazes de despertar emoções, reações, leis, oração, músicas e imagens esteticamente emolduradas e inspiradas."(p. 17).

6. Entre os grupos que se definem feministas no movimento hip hop, salientamos o "Minas da Rima". Em entrevista concedida à autora em 2005, uma de suas integrantes relata "que pra mim o que é ser feminista não se contra os homens, é lutar pelos direitos iguais das mulheres ... é lutar contra todas as formas de opressão e discriminação existente". Para leitura aprofundada acerca do feminismo no âmbito brasileiro sugiro: Moraes, M. L. Q. (2001). Dossiê: Feminismo em questão, questões do feminismo. Cadernos Pagu (Núcleo de Estudos de Gênero/ Unicamp), 16.

7. Uma descrição mais detalhada sobre esta relação pode ser obtida nas dissertações de mestrado defendidas no programa da Faculdade de Educação da Unicamp: "Mulheres no hip hop: Identidades e representações" de minha autoria, defendida em $2006 \mathrm{e}$ "Rap de batom: Família, educação e gênero no universo rap" de autoria de Mariana Semião de Lima, defendida em 2005.

\section{Referências}

Andrade, E. N. (1996). Movimento negro juvenil: Um estudo de caso sobre jovens rappers de São Bernardo do Campo. Dissertação de Mestrado não-publicada, Faculdade de Educação, Universidade de São Paulo, SP.

Castro, M. C. (2001). Gênero e poder. Leituras transculturais: Quando o sertão é mar, mas o olhar estranha, encalha em recifes. Cadernos Pagu (Núcleo de Estudos de Gênero), 16.

Chacham, A. S., \& Maia, M. (2004). Corpo e sexualidade da mulher brasileira. In G. Venturi, M. Recamán \& S. Oliveira (Eds.), A mulher brasileira no espaço público e privado. São Paulo, SP: Editora da Fundação Perseu Abramo.

Damatta, R. (1991). A casa e a rua. Espaço, cidadania, mulher e morte no Brasil. Rio de Janeiro, RJ: Guanabara Koogan.

Entrevista explosiva. (2005, jun.). Revista Caros Amigos, 9(99), p. 
30-35.

Guareschi, M. F., \& Bruschi, M. E. (Eds.). (2003). Psicologia social nos estudos culturais: Perspectivas e desafios para uma nova psicologia social. Petrópolis, RJ: Vozes.

Guasco, P. P. M. (2001). Num país chamado periferia: Identidade e representação da realidade entre os rappers de São Paulo. Dissertação de Mestrado não-publicada, Faculdade de Filosofia, Letras e Ciências Humanas, Universidade de São Paulo, SP.

Guimarães, M. E. (1998). Do samba ao rap: A música negra no Brasil. Campinas, SP: Editora da Universidade de Campinas.

Herschmann, M. (1997). Abalando os anos 90: Funk, hip hop, globalização, violência e estilo cultural. Rio de Janeiro, RJ: Rocco.

Kehl, M. R. (2000). Radicais, raciais, racionais, a grande fratria do rap na periferia de São Paulo. São Paulo em Perspectiva, 13(13).

Lima, M. S. (2005). Rap de batom: Família, educação e gênero no universo hip hop. Dissertação de Mestrado não-publicada, Programa de Pós-graduação em Educação, Universidade Estadual de Campinas, SP

Lipovetsky, G. (2000). A terceira mulher: Permanência e revolução do feminino. São Paulo, SP: Companhia das Letras.

Lourenço, M. L. (2002). Cultura, arte, política \& O movimento hip hop. Curitiba, PR: Chain.

Magro, V. M. M. (2002, ago.). Adolescentes como autores de si próprios: Cotidiano, educação e o hip hop. Caderno Cedes, Campinas, 22(57), 63-75.

Matsunaga, P. S. (2006). Mulheres no hip hop: Identidades e representações. Dissertação de Mestrado não-publicada, Programa de Pós-graduação em Educação, Universidade Estadual de Campinas, SP.

Mclaren, P. (2000). Pedagogia Gangsta e Guetocentrismo: A Nação Hip-Hop como uma esfera contrapública. In P. Mclaren. Multiculturalismo revolucionário. Pedagogia do dissenso para o novo milênio. Porto Alegre, RS: Artes Médicas Sul.

Moscovici, S. (2003). Representações sociais: Investigações em psicologia social (P. Guareschi, Trad.). Petrópolis, RJ: Vozes.

Pimentel, S. K. (1999). Hip-Hop como utopia. In E. N. Andrade (Ed.), Rap e educação, rap é educação (pp. 103-112). São Paulo, SP: Summus.

Porto, M. (2004). Em Busca de Kairos. In G. Venturi, M. Recamán $\&$ S. Oliveira (Eds.), A mulher brasileira no espaço público e privado. São Paulo, SP: Editora da Fundação Perseu Abramo.

Rose, T. (1997). Um estilo que ninguém segura: Política, estilo e a cidade pós-industrial no hip hop. In M. Herschmann. Abalando os anos 90: Funk, hip hop, globalização, violência e estilo cultural (pp. 192-213). Rio de Janeiro, RJ: Rocco.

Saffioti, H. (2004). Gênero e patriarcado: Violência contra mulheres. In G. Venturi, M. Recamán \& S. Oliveira (Eds.), A mulher brasileira no espaço público e privado. São Paulo, SP: Editora da Fundação Perseu Abramo.

Sarti, C. (1985). É sina o que a gente traz. Ser mulher na periferia urbana. 1995. Dissertação de Mestrado não-publicada, Programa de Pós-graduação em Ciências Sociais, Universidade de São Paulo, SP.

Silva, J. C. G. (1999). Arte e educação: A experiência do hip-hop paulistano. In E. N. Andrade (Ed.), Rap e educação, rap é educação (pp. 23-38). São Paulo, SP: Summus.

Souza, A. R. (2005). A favela de influência: Uma análise das práticas discursivas dos Racionais MCs. Dissertação de Mestrado não-publicada, Programa de Pós-graduação em Lingüística, Universidade Estadual de Campinas, SP.

Souza, T. (2002). Formações identitárias de grupos e comunida- des singulares: $O$ esgotamento do individualismo moderno $e$ os sentidos dos comunitarismos atuais. Piracicaba, SP: Universidade Metodista de Piracicaba.

Tella, M. A. P. (1999). Rap, memória e identidade. In E. N. Andrade (Ed.), Rap e educação, rap é educação (pp. 55-63). São Paulo, SP: Summus.

Tella, M. A. P. (2000). Atitude, arte, cultura e autoconhecimento: $O$ rap como voz da periferia. 2000. Dissertação de Mestrado nãopublicada, Pontifícia Universidade Católica de São Paulo, SP.

Thompson, J. B. (1995). Ideologia e cultura moderna: Teoria crítica na era dos meios de comunicação de massa. São Paulo, SP: Vozes.

Priscila Saemi Matsunaga é graduada em Psicologia pela Universidade Metodista de Piracicaba, Mestre em

Educação pela Universidade Estadual de Campinas. Docente do Curso de Psicologia na Universidade Federal de Goiás, campus Jataí. Endereço para correspondência: Rua Riachuelo, no. 1530 - Setor Samuel Graham Caixa postal 03 Cep 75.804-020, Jataí (GO), 75 802-105. Tel./Fax: (64) $3632-0000$, , (64) 3636-8736 priscilamatsunaga@bol.com.br

As Representações Sociais da Mulher no Movimento Hip Hop Priscila Saemi Matsunaga

Recebido: 16/03/2007

$1^{a}$ revisão: $13 / 11 / 2007$

Aceite final: 30/11/2007 